\title{
SIGNIFICADO DO CUIDAR E SEUS SENTIMENTOS PARA EQUIPE DE ENFERMAGEM DIANTE DA CRIANÇA EM TRATAMENTO ONCOLÓGICO
}

\section{SIGNIFICANCE OF CARE FOR NURSING STAFF ON THE CHILD'S CANCER TREATMENT}

\section{IMPORTANCIA DE LA ATENCIÓN POR EL PERSONAL DE ENFERMERÍA EN EL TRATAMIENTO DEL CÁNCER DEL NIÑ̃O}

\author{
Camila Morena Margato Silva ${ }^{1}$, Maria Paula Custódio Silva ${ }^{2}$, Débora De Oliveira Ferreira ${ }^{3}$, \\ Jesislei Bonolo do Amaral ${ }^{4}$, Jurema Ribeiro Luiz Gonçalves ${ }^{5}$, Divanice Contim ${ }^{6}$
}

\section{RESUMO}

Objetivo: trata-se de uma pesquisa qualitativa, descritiva, cujo objetivo do estudo foi compreender os significados e os sentimentos manifestados pela equipe de enfermagem durante o cuidar num serviço de oncologia pediátrica. Método: participaram do estudo dez profissionais de enfermagem que atuavam nesse serviço. Os dados foram coletados por meio de entrevista semiestruturada no período de dezembro de 2014 a janeiro de 2015. As entrevistas foram gravadas e transcritas na íntegra e submetidas à análise de conteúdo. Resultados: foram identificadas três categorias: o significado do cuidado; conforto e humanização; o envolvimento inevitável e a busca do equilíbrio emocional. Conclusão: concluiu-se que os sentimentos de empatia, compaixão e apego são envolvidos durante o trabalho cotidiano da equipe de enfermagem, sendo preciso apoio psicológico a essa para evitar o desequilíbrio mental da equipe.

Descritores: Enfermagem oncológica. Cuidado da Criança. Emoções.

\begin{abstract}
\footnotetext{
${ }^{1}$ Enfermeira.

${ }^{2}$ Residente de Enfermagem em Neonatologia.

${ }^{3}$ Residente de Enfermagem em Neonatologia.

${ }^{4}$ Mestre em Enfermagem e Docente na UFTM.

${ }^{5}$ Doutora em Enfermagem e Docente na UFTM.

${ }^{6}$ Doutora em Enfermagem e Docente na UFTM.
}

Objective: this is a qualitative and descriptive study whose objective was to understand the meanings and feelings expressed by the nursing staff during the care in a pediatric oncology service. Method: participated in the study ten nurses who worked in this service. Data were collected through semi-structured interviews from December 2014 to January 2015.As interviews were recorded and transcribed and subjected to content analysis. Results: three categories were identified: the meaning of care, comfort and humanization, the inevitable involvement and seeking emotional balance. Conclusion: it was concluded that the feelings of empathy, compassion and dedication are involved during the daily work of the nursing staff, being precise psychological support to that to avoid the team's mental imbalance.

Descriptors: Oncology nursing. Child Care. Emotions. 


\section{RESUMEN}

Objetivo: Se trata de un estudio cualitativo y descriptivo que tuvo como objetivo comprender los significados y sentimientos expresados por el personal de enfermería durante la atención en un servicio de oncología pediátrica. Método: Participó en las enfermeras estúdio diez que trabajaron en este servicio. Los datos fueron recolectados a través de entrevistas semiestructuradas a partir de diciembre de 2014 hasta enero de entrevistas 2015. As fueron grabadas y transcritas y sometidas al análisis de contenido. Resultado: Se identificaron tres categorías: el significado de la atención, la comodidad y la humanización, la participación inevitable y buscando el equilibrio emocional. Conclusión: Se concluyó que los sentimientos de empatía, compasión y dedicación están involucrados en el trabajo diario del personal de enfermería, siendo preciso apoyo psicológico que para evitar el desequilibrio mental del equipo.

Descriptores: Enfermería Oncológica. Cuidado del niño. Emociones.

\section{INTRODUÇÃO}

O cuidado no campo da oncologia pediátrica desenvolve-se por meio da assistência preventiva, curativa e paliativa. Ações como aconselhamento genético e orientações quanto aos hábitos de vida saudável configuram-se como o cuidado preventivo. A assistência curativa atua durante o diagnóstico, tratamento e controle, sendo importante a presença de uma equipe multiprofissional para melhor assistência. $^{1,2}$ Quanto aos cuidados paliativos, estes são empregados para melhorar a qualidade de vida dos pacientes e de suas famílias que enfrentam problemas associados a doenças sem possibilidades de cura. ${ }^{3}$

As crianças e adolescentes com câncer são encaminhadas para tratamento em estágio avançado da doença. Por causa do diagnóstico tardio, desinformações dos pais, medo, dificuldade de acesso aos serviços e tecnologias de rastreamento e por características peculiares de alguns tipos de tumores nessa faixa etária que possuem um crescimento rápido e são mais invasivos. Assim é de grande importância investimentos para o desenvolvimento de ações na rede de atenção à saúde que permitam o diagnóstico precoce e tratamento adequado. ${ }^{4,5}$

A assistência em oncologia requer da equipe multiprofissional de saúde uma prática resolutiva, seja qual for a situação da doença vivenciada pela criança e seus desdobramentos no cotidiano familiar. A enfermagem é parte integrante dessa equipe, composta por técnicos de enfermagem e enfermeiros, presente na assistência a essas crianças e atua de forma ativa durante seu tratamento. ${ }^{3}$ Nesse contexto, é importante que a equipe seja capaz de compreender os sentimentos que surgem ao prestarem o cuidado, tanto da criança, familiares, como do próprio profissional. Além de terem conhecimento sobre a doença e a qual fase do 
desenvolvimento natural essa criança encontra-se. ${ }^{2,6-9}$

Lidar com a doença e com as formas de tratamento, assim como outros eventos correlacionadas à imagem corporal, fatores estressantes e questões familiares podem levar a equipe multidisciplinar ao sofrimento, ansiedade, tristeza, frustração, entre outros sentimentos, em especial a equipe de enfermagem por atuar de forma ativa no cuidado. $^{7,8,10,11}$

As situações estressoras das neoplasias pediátricas não estão ligadas somente à associação do sofrimento, complicações e morte ocasionados pelo câncer, mas também com a percepção de que há uma incompatibilidade desse tema com a infância. ${ }^{10-13} \mathrm{O}$ sofrimento também advém diante da morte da criança, por uma interrupção de uma vida que estava iniciando, privando a criança de sua infância, do desenvolvimento do seu ciclo vital, não tendo essa, a oportunidade de trabalhar, casar, ter filhos, envelhecer com qualidade de vida. Enfim, não desfrutar de uma vida de promessas e esperança da própria cura. ${ }^{14}$

Alguns integrantes da equipe de enfermagem conseguem lidar saudavelmente com os sentimentos e emoções que o convívio e cuidado diário estabelece, entretanto é visível que parte desses profissionais podem apresentar dificuldades no manejo de tais sentimentos e emoções. ${ }^{11}$ Ao reconhecer os sentimentos e as formas de enfrentamento busca-se o equilíbrio emocional a fim de evitar o desgaste mental, assistindo a criança de forma humanizada com qualidade na assistência, sem comprometimento com a saúde mental de tais profissionais.

Cuidar de crianças com doença oncológica e lidar com a morte, estar com a família diariamente, com suas angústias e sofrimentos são situações enfrentadas pela equipe de enfermagem. ${ }^{6-8,10}$ É necessário o conhecimento das percepções e sentimentos relacionados ao cuidar em oncologia pediátrica da equipe de enfermagem. Nessa direção tornam-se necessárias algumas reflexões que podem servir para minimizar os efeitos do câncer para a equipe de enfermagem em relação ao seu profissionalismo, buscando compreender o significado dessa relação de cuidado e sentimento, promovendo um atendimento interacional equilibrado, expressivo e de qualidade. , $7,11,13,14^{-}$

Nessa perspectiva o objetivo desse estudo foi compreender os significados e os sentimentos manifestados pela equipe de enfermagem durante o cuidar num serviço de oncologia pediátrica. 


\section{METODOLOGIA}

Trata-se de uma pesquisa descritiva, com abordagem qualitativa, desenvolvida na Unidade de Internação da Pediatria, de um Hospital filantrópico, localizado no município de Uberaba-MG, que oferece atendimento médico-hospitalar em diversas áreas e especialidades, inclusive oncologia pediátrica. Os sujeitos foram membros da equipe de enfermagem com mais de um ano de experiência neste serviço em razão da necessidade dos mesmos terem experiência acumulada e estar trabalhando na época da coleta. Foram excluídos da pesquisa os indivíduos que não exerciam suas atividades laborais no referido serviço pesquisado ou que não se incluíam nas categorias profissionais selecionadas. A coleta de dados ocorreu no período de dezembro de 2014 a janeiro de 2015.

O número de participantes foi definido pelo critério de saturação dos dados que permite a análise mais detalhada das relações estabelecidas no ambiente da pesquisa e a compreensão de significados, sistemas simbólicos e de classificação, códigos, práticas, valores, atitudes, ideias e sentimentos. ${ }^{15}$

A produção do material empírico ocorreu no período de dezembro de 2014 a janeiro de 2015. Os dados foram coletados por meio de entrevista semiestruturada. A primeira parte da entrevista foi composta pelo levantamento dos dados sócio demográficos: gênero, idade, tempo de formação, tempo de experiência, tempo de serviço nesta instituição, formação profissional, carga horária semanal nesta instituição, turno de trabalho. $\mathrm{Na}$ segunda etapa foi realizada uma entrevista semiestruturada, com as seguintes questões: a) qual o significado do cuidar atribuído a equipe de enfermagem que atua na oncologia pediátrica? b) quais sentimentos vivenciados durante a prestação do cuidado à criança e adolescente com câncer?

As entrevistas foram previamente agendadas, conforme a disponibilidade dos participantes. Após a assinatura do Termo de Consentimento Livre e Esclarecido (TCLE), os participantes foram entrevistados individualmente e, em sala previamente reservada, com gravação em aparelho de áudio. Após, foram transcritas e armazenadas em banco de dados eletrônico, visando à análise e interpretação. As entrevistas foram disponibilizadas em arquivos digitais e tiveram duração média de 30 a 50 minutos.

O referencial metodológico utilizado foi o da Análise de Conteúdo, constituída pelas etapas: pré-análise; exploração do material; e tratamento dos resultados, inferência e interpretação. Os 
dados foram codificados a partir das unidades de registro. ${ }^{16}$

Para categorização utilizou-se códigos, como: “[...]” quando um fragmento da fala foi excluído; “...” para ilustrar as pausas que ocorreram durante a entrevista. Para preservar o anonimato dos sujeitos foram identificados pela letra $\mathrm{E}$ (entrevista), seguida de um número que representava a ordem de ingresso no estudo.

O projeto foi aprovado pelo Comitê de Ética e Pesquisa da Universidade Federal do Triângulo Mineiro sob o parecer $n^{\circ}$ 2311/2012. Foram respeitados os princípios éticos para pesquisas que envolvem seres humanos, de acordo com a Resolução de $n^{\circ}$ 196/96, do Conselho Nacional de Saúde-Ministério da Saúde.

\section{RESULTADOS E DISCUSSÃO}

Foram entrevistados dez profissionais com idade de 22 a 45 anos, todos do sexo feminino, três eram enfermeiras especialistas e sete técnicas de enfermagem. Em relação ao tempo de atuação profissional, a média foi de três anos atuantes, somente uma com seis meses de experiência.

O processo de análise de conteúdo das entrevistas permitiu identificar três categorias: Cuidado, conforto e humanização; Constituição de vínculo e Busca do equilíbrio emocional.

\section{Cuidado, conforto e humanização}

Essa categoria está relacionada à interação da equipe de enfermagem durante sua assistência às crianças em tratamento antineoplásico. A prestação de cuidado faz parte do cotidiano de tais profissionais, sendo relevante $\mathrm{o}$ conhecimento, compreensão e a percepção dos atores promotores desse cuidado.

A análise revelou que os profissionais de enfermagem acreditam que o cuidado envolve aspectos psicossociais não somente o tratamento medicamentoso:

Significa um completar o cuidado, porque tanto o tratamento medicamentoso é necessário, como o afetivo, o olhar, o ouvir, o escutar, o tocar, esse eu acho que complementa, e que não pode faltar (e1).

[...] a gente vai fazer uma medicação tem que explicar, tem que conversar da forma que eles entendam (e8).

A pesquisa sinaliza que na perspectiva da integralidade, o cuidado em oncologia pediátrica requer recursos materiais e terapêuticos, tornando-se um desafio para equipe de saúde, exigindo de tais profissionais preparo adequado e sensibilidade ao cuidar dessas crianças, inserindo nesse contexto abordagem 
psicológica, a fim de auxiliar no enfrentamento da situação. ${ }^{10,11,17}$

Além da preocupação de oferecer um cuidado não voltado somente para a prática assistencial e medicamentosa, evidencia-se a preocupação com a prestação de conforto ao paciente e seu familiar como é descrito abaixo:

Então é um cuidado muito delicado, porque geralmente é só cuidado paliativo, né. Então tem que dar só o conforto pra elas (e2).

Um pouco de ouvir, entender, cuidado com as mães também, com o familiar (e4).

Oferecer apoio e conforto aos familiares e à criança, nesse momento, proporciona alívio para ambos e auxilia na prática assistencial. É importante salientar que o cuidado adiciona ações que envolvem respeito e conhecimento dos valores de quem recebe o cuidado e busca de forma sistemática proporcionar conforto por meio de ações de promoção à saúde. $^{7,10,13,14,18}$ Para a equipe de enfermagem a humanização é idealizada e essencial, tendo em vista que o ser cuidado seja assistido em sua plenitude, então é necessário o envolvimento com o familiar e com a criança, a fim de oferecer conforto e uma assistência de qualidades.

É necessário que entre o profissional de enfermagem e a criança com câncer seja estabelecida uma relação de confiança, constituída pelo vínculo entre familiares, com o objetivo de facilitar e aprimorar a prestação dos cuidados, sendo essa uma importante ferramenta para a reabilitação do paciente, minimizando os prejuízos e traumas da hospitalização. Dessa forma a assistência humanizada tende a oferecer a criança um ambiente aconchegante para suavizar os fatores que causam estresse à criança e à família. ${ }^{4}$

A análise sinaliza que a hospitalização, muda a rotina na vida dessas crianças, sendo importante que a equipe de enfermagem ofereça abertura, para o diálogo, para a escuta e acolhimento da criança e dos sujeitos envolvidos bem como implementem estratégias para favorecer a humanização da assistência. ${ }^{6,7,10,14,19} \mathrm{O}$ cuidado ideal, na percepção das participantes, deve ser humanizado e abranger toda família dessa criança durante sua internação. A prática do acolhimento é essencial para efetivação desse cuidado, como é possível identificar nos seguintes enunciados:

Ele não é unificado, porque cuidar de uma criança, não é só da criança, a gente cuida da criança e da família, e a gente tem que ter um cuidado maior, uma humanização maior (e3).

Tem todo um[...] contexto né, vem à mãe, a criança não interna sozinha, começa pelo o acolhimento, é muito importante, porque ficam todos muito apreensivos, com o que vai acontecer como vai acontecer com o que está por vir (e6).

Compreende-se que a humanização é uma prática com a intenção de tornar efetiva a assistência biopsicossocial e 
espiritual do indivíduo crítico. Envolve desde o paciente sob cuidados até os que estão envolvidos no processo saúdedoença. As atividades da equipe de enfermagem nas instituições de saúde devem ser direcionadas ao acolhimento e integralidade do paciente com a finalidade de humanizar a assistência. $^{20}$ Como foi possível ver nos depoimentos, tal preocupação é evidente, sendo que a busca pela humanização do cuidado torna a internação da criança menos traumatizante e abrange o conforto e cuidado para todos os envolvidos.

\section{A constituição de vínculo}

A análise dessa categoria permitiu inferir que a equipe de enfermagem lida constantemente com o medo, insegurança e sofrimento das crianças e seus familiares, e, tenta trabalhar suas aflições internas diante disso. Uma das formas que esses profissionais recorrem para compreender é ajudando e refletindo sobre o outro, desenvolvendo empatia e compaixão por aqueles envolvidos nesse processo doloroso, como é possível visualizar nos seguintes trechos:

Eu acho que é um sentimento de compaixão, de se colocar no lugar do outro, sabe eu penso se fosse comigo, se fosse com alguém que eu conheço, ou se fosse com meu filho [...] (e1).

[...]Você se coloca no lugar da mãe, e você se coloca no lugar e pensa que poderia ser meи filho, poderia ser meu sobrinho, eи acho que o despertar é sempre, ligado a alguma questão familiar, por ser uma criança [...] (e3).

Como consequência da longa permanência da criança e o constante contato e aproximação com a equipe de enfermagem, estes sentem a perda do paciente como se fosse alguém da sua própria família ou de alguém que amam muito. $^{15}$

Neste cenário a proximidade constante e o desenvolvimento da empatia trazem consigo, o carinho e apego pelas crianças. A busca pelo conforto, a tentativa de suavizar o tratamento e aproximar o ambiente hospitalar do cenário infantil também é evidente, de acordo os depoimentos:

[...] Pra gente[...] a única parte difícil é[...] que a gente se apega a eles, então eu acho que é a única coisa, de diferente né. A gente aprende, porque a gente brinca, pode ver que eles ficam aqui no posto de enfermagem, eles brincam $[\ldots](e 8)$.

Então acaba que a gente se apega muito nelas, porque elas ficam mais aqui do que em casa $[\ldots](e 2)$.

Além do envolvimento afetivo, a empatia e apego, os cuidados com crianças em tratamento contra o câncer, fazem com que muitos profissionais reflitam sobre as próprias vidas em relação à finitude, tal reflexão foi apontada no seguinte depoimento:

[...] Por ser uma criança, não fez nada ainda na vida, a gente pré-julga que não tem nada 
para pagar na terra ainda[...] eles têm muito ainda o que viver, tem que estudar crescer primeiro, passar pelas fases, e ainda a pessoa não viveu nada, a gente se liga muito ao valor da vida, do questionamento que viveu tão pouco [...] tão poucos momentos pra já estar enfrentando aquele problema, [...] às vezes o problema é maior que a criança $[\ldots](e 3)$.

Ao concluir essa categoria, observa-se que a assistência de enfermagem vai além do desenvolvimento de procedimentos, tal prática é mais bem aplicada quando a família é incluída no tratamento, tornando à mais humanizada quando se desenvolve empatia diante da situação, aproximando o universo infantil, tentando levar ao indivíduo um conforto, como também compreender as reações da criança, suas inseguranças, limitações e fases da vida que podem ser interrompidas. $^{6,8,11,13,14,21}$

\section{Em busca do equilíbrio emocional}

Sentimentos são evidentes por causa da empatia e apego, visto que o convívio contínuo, a aproximação com a criança e com seus familiares fazem com que o profissional se torne suscetível às emoções.

Entretanto, situações de vida e morte são constantes, o que acaba por tocar a equipe de enfermagem, fazendo a despertar sentimentos que levam a buscar o equilíbrio e bem-estar ${ }^{6,10}$ No entanto as dificuldades em manejar as emoções em relação as crianças com doença oncológica é uma realidade, uma vez que esses profissionais não têm apoio, orientação e respaldo para essa situação. ${ }^{11}$ Estes eventos podem resultar em desequilíbrio emocional, levando a esses profissionais ao afastamento temporário do ambiente de trabalho. ${ }^{12,13,18,20}$

A análise sinaliza para a reflexão sobre como proceder na manutenção do equilíbrio das emoções que surgem como pode ser verificado nos seguintes depoimentos:

Tem que tentar sempre, tratar o paciente, com sensibilidade, mas não usar muito a emoção, usar mais a razão, para o paciente não sentir[...] $e$ ter um pouquinho de cuidado de não levar o trabalho do hospital para casa, porque senão você começa a ter os problemas emocionais em casa também (e7).

Para cuidar da criança com câncer ter que ter sentimento no coração, ser sensível, mais tem que ser racional, agir com a razão se não nós não conseguimos cuidar da criança como ela precisa (e3)

O trabalho em oncologia pode estar relacionado aos pacientes terminais, o que pode influenciar um confronto com a própria finitude, suas limitações geram uma sensação de impotência. Em decorrência disso, manifesta o sentimento de medo e depressão, por não saberem lidar com a perda, e se identificarem com o paciente. $^{2,6,7,10,12,13}$ 
Nas falas a seguir, a impotência e o medo da perda são sentimentos presentes na equipe de enfermagem:

Então existe o medo, a gente tem dificuldades[...]eu ainda não me acostumei com alguma perda, é difícil a gente lidar com essa situação, porque a gente não tem um cuidado específico pra gente, e quando acontece tem que aprender na hora lidar com a situação e aprender a tocar pra frente (e4).

Porque às vezes você luta por aquela criança, e acaba perdendo e você dedicou tempo[...] uma situação de impotência (e8).

É possível identificar nessas falas; o medo da aproximação por causa do despreparo emocional, além disso, o medo da perda da criança gera situação de impotência, de trabalho inacabado.

Para enfrentar o cotidiano alguns dos profissionais que prestam o cuidado mantêm-se imparciais, evitam o envolvimento com a criança e consequentemente o sofrimento. Em contrapartida outros profissionais buscam maior aproximação com seus pacientes, a fim de compreender as necessidades dos mesmos para um cuidado qualificado, promovendo conforto e realização profissional diminuindo assim o nível de estresse. ${ }^{7,11,18}$ Dessa forma nessa categoria observa-se que o cuidar é uma ação que envolve um processo circular, dinâmico e gradual, que o conflito ou a dúvida sob o cuidado exercido fazem parte desse processo. $^{18}$ Assim ocorre a busca por compreender e atender as necessidades do paciente, isso ocorre a partir do momento da interação e do estabelecimento do vínculo afetivo entre as partes envolvidas. A equipe de enfermagem pode usar dessa relação empática para auxiliar no assistir o paciente em sua individualidade, porém este ato pode acarretar também problemas psicossociais para tais profissionais. ${ }^{11,13,15,18,20}$

Diante disso, por causa da ocorrência de tais problemas é necessário propor estratégias para suprimir a falta de preparo e respaldo dos profissionais de enfermagem que experienciam o assistir a criança com doença oncológica. ${ }^{6,7}$

\section{CONSIDERAÇÕES FINAIS}

$\mathrm{O}$ estudo possibilitou mostrar que durante o trabalho cotidiano da equipe de enfermagem, esses aproximam-se das crianças em tratamento oncológico e de sua família a fim de estabelecer vínculo e oferecendo cuidado e conforto.

Frente à questão do significado do cuidar de crianças durante tratamento contra o câncer, foi possível identificar que, para os integrantes da equipe de enfermagem esse cuidado envolve vínculo, escuta, não limitando ao tratamento medicamentoso, o que é importante para a qualidade do atendimento, a humanização, 
não somente do indivíduo em si, mas englobando também sua família.

O envolvimento é imprescindível entre a criança e os profissionais, e, diante do sofrimento causado pela situação estressante da criança, foi possível refletir e compreender o ser cuidado em sua plenitude, estabelecendo empatia, desenvolvendo compaixão e apego, com a finalidade de aproximar a assistência do cenário infantil, amparando e oferecendo conforto.

O estudo possibilitou a reflexão das necessidades de cuidado voltadas para essa

\section{REFERÊNCIAS}

1. Silva JKO, Moreira Filho DC, Mahayri N, Ferraz RO, Friestino FS. Câncer infantil: monitoramento da informação através dos registros de câncer de base populacional. Rev Bras Cancerol. [Internet]. 2012 [citado em 04 jun 2017]; 58(4):681-86. Disponível em:

http://www.inca.gov.br/rbc/n_58/v04/pdf/1 4-revisao-literatura-cancerinfantilmonitoramento-informacao-atravesregistros-cancer-base-populacional.pdf

2. Sanches MVP, Nascimento LC, Lima RAG. Crianças e adolescentes com câncer em cuidados paliativos: experiência de familiares. Rev Bras Enferm. [Internet]. 2014 [citado em 04 jun 2017]; 67(1):28-35. Disponível em:

http://www.scielo.br/pdf/reben/v67n1/0034 -7167-reben-67-01-0028.pdf. doi: http://dx.doi.org/10.5935/00347167.20140003

3. Guimarães TM, Silva LF, Santo FHE, Moraes JRMM, Pacheco STA. Cuidado paliativo em oncologia pediátrica na formação do enfermeiro. Rev Gaúch equipe, é interessante proporcionar espaços e apoio psicológico, individual ou em grupo, com finalidade de abertura $\mathrm{e}$ revelação de sentimentos que ficam ocultos e levam ao sofrimento mental dos mesmos. É necessário o reconhecimento das instituições de saúde de tal situação, para que assim promovam o preparo desses profissionais que atuam em oncologia pediátrica, oferecendo-lhes capacitação e apoio psicológico adequado.

Enferm. [Internet]. 2017 [citado em 13 mar 2018]; 38(1):e65409. Disponível em: http://www.scielo.br/pdf/rgenf/v38n1/0102 -6933-rgenf-1983-144720170165409.pdf

4. Souza CA, Jerico MC, Perroca MG. Mapeamento de intervenções/atividades dos enfermeiros em centro quimioterápico: instrumento para avaliação da carga de trabalho. Rev Latinoam Enferm. [Internet]. 2013 [citado em 04 jun 2017]; 21(2):49299. Disponível em: http://www.scielo.br/pdf/rlae/v21n2/pt_01 04-1169-rlae-21-02-0492.pdf

5. Instituto Nacional de Câncer José Alencar Gomes da Silva, Coordenação de Prevenção e Vigilância. Estimativa 2014: incidência de câncer no Brasil. Rio de Janeiro: INCA; 2014.

6. Borges AA, Lima RAG, Dupas, G. Segredos e verdades no processo comunicacional da família com a criança com câncer. Esc Anna Nery Rev Enferm. [Internet]. 2016 [citado em 04 jun 2017]; 20(4): e20160101. Disponível em: http://www.eean.edu.br/detalhe_artigo.asp ?id=1464. doi: 
http://dx.doi.org/10.5935/1414-

8145.20160101

7. Rezende MCC, Ferreira Neto JL.

Processos de subjetivação na experiência de uma equipe de enfermagem em oncologia. Rev Psicol Saúde. [Internet]. 2013 [citado em 04 jun 2017]; 5(1):40-48. Disponível em: http://pepsic.bvsalud.org/pdf/rpsaude/v5n1 /v5n1a07.pdf

8. Anjos C, Espírito Santo FH, Carvalho EMMS. O câncer infantil no âmbito familiar: revisão integrativa. REME Rev Min Enferm. [Internet]. 2015 [citado em 04 jun 2017]; 19(1):227-33. Disponível em:

http://www.reme.org.br/artigo/detalhes/998

9. Mutti CF, Padoin SMM, Paula CC. Espacialidade do ser-profissional-deenfermagem no mundo do cuidado à criança que tem câncer. Esc Anna Nery Rev Enferm. [Internet]. 2012 [citado em 15 mar 2018]; 16(3):493-499. Disponível em: http://www.scielo.br/pdf/ean/v16n3/10.pdf

10. Oliveira MCL, Firmes PR. Sentimentos dos profissionais de enfermagem em relação ao paciente oncológico. REME Rev Min Enferm. [Internet]. 2012 [citado em 04 jun 2017]; 16(1):91-7. Disponível em:

http://www.reme.org.br/artigo/detalhes/505

11. Amador DD, Gomes IP, Reichert APS, Collet N. Repercussões do câncer infantil para o cuidador familiar: revisão integrativa. Rev Bras Enferm. [Internet]. 2013 [citado em 04 jun 2017]; 66(2):26770. Disponível em: http://www.scielo.br/pdf/reben/v66n2/17.p df

12. Souza LF, Misko MD, Silva L, Poles K, Santos MR, Bousso RS. Morte digna da criança: percepção de enfermeiros de uma unidade de oncologia. Rev Esc Enferm USP. [Internet]. 2013 [citado em 04 jun 2017]; 47(1): 30-37. Disponível em: http://www.scielo.br/pdf/reeusp/v47n1/a04 v47n1.pdf. dois:

http://dx.doi.org/10.1590/S0080-

62342013000100004
13. Fermo VC, Lourençatto GN, Medeiros TS, Anders JC, Souza AIJ. O diagnóstico precoce do câncer infanto juvenil: o caminho percorrido pelas famílias. Esc Anna Nery Rev Enferm. [Internet]. 2014 [citado em 04 jun 2017]; 18(1):54-9. Disponível em: http://www.scielo.br/pdf/ean/v18n1/14148145-ean-18-01-0054.pdf. doi: http://dx.doi.org/10.5935/14148145.20140008

14. Salimena AMO, Teixeira SR, Amorim TV, Paiva ACPC, Melo MCSC. Estratégias de enfrentamento usadas por enfermeiros ao cuidar de pacientes oncológicos. Rev Enferm UFSM. [Internet]. 2013 [citado em 04 jun 2017]; 3(1):8-16. Disponível em: https://periodicos.ufsm.br/index.php/reufs m/article/view/6638. doi: http://dx.doi.org/10.5902/217976926638

15. Fontanella BJB, Luchesi BM, Saidel MGB, Ricas J, Turato ER, Melo DG. Amostragem em pesquisas qualitativa: proposta de procedimentos para constatar saturação teórica. Cad Saúde Pública. [Internet]. 2011 [citado em 04 jun 2017]; 27(2):389-94. Disponível em: http://www.scielo.br/pdf/csp/v27n2/20.pdf

16. Bardin L. Análise de conteúdo. Lisboa: Edições 70; 2011.

17. Amador DD, Gomes IP, Coutinho SED, Costa TNA, Collet N. Concepção dos enfermeiros acerca da capacitação no cuidado à criança com câncer. Texto \& Contexto Enferm. [Internet]. 2011 [citado em 04 jun 2017]; 20(1):94-101. Disponível em:

http://www.scielo.br/pdf/tce/v20n1/11.pdf. doi: http://dx.doi.org/10.1590/S010407072011000100011

18. Avanci BS, Carolindo FM, Góes FGB, Netto, NPC. Cuidados paliativos à criança oncológica na situação viver/morrer: a ótica do cuidar em enfermagem. Esc Anna Nery Rev Enferm. [Internet]. 2009 [citado em 04 jun 2017]; 3(4):708-16. Disponível em:

http://www.scielo.br/pdf/ean/v13n4/v13n4 a04.pdf. doi: 
http://dx.doi.org/10.1590/S1414-

81452009000400004

19. Maranhão TA, Melo BMS, Vieira TS,

Veloso AMMV, Batista NNLAL. A

humanização no cuidar da criança

portadora de câncer: fatores limitantes e

facilitadores. J Health Sci Inst. [Internet].

2011 [citado em 04 jun 2017]; 29(2):106-9.

Disponível em:

https://www.unip.br/comunicacao/publicac

oes/ics/edicoes/2011/02_abr-

jun/V29_n2_2011_p106-109.pdf

20. Duarte MLC, Noro A. Humanização: uma leitura a partir da compreensão dos profissionais da enfermagem. Rev Gaúch Enferm. [Internet]. 2010 [citado em 04 jun 2017]; 31(4):685-92. Disponível em:

http://www.scielo.br/pdf/rgenf/v31n4/a11v 31n4.pdf. doi:

http://dx.doi.org/10.1590/S1983-

14472010000400011

RECEBIDO: 12/09/17

APROVADO: $30 / 07 / 18$

PUBLICADO: 09/18 